\title{
The search for new drugs for the treatment of leprosy
}

\author{
M HOOPER \\ Department of Pharmaceutical Chemistry, Faculty of Pharmaceuti- \\ cal Sciences, Sunderland Polytechnic, Sunderland SR2 7EE
}

\section{Accepted for publication 10 July 1984}

\begin{abstract}
Summary The reasons for wanting to develop completely novel antileprotic drugs are stated. A number of promising lead compounds are identified from a consideration of the biochemistry and structure of $M$. leprae and the natural product, oil of chaulmoogra. Their structures provide a rational basis for the development of programmes of research which could lead to new antileprotic agents. Some early success in one such programme is reported.
\end{abstract}

The first-line drugs currently used in the treatment of leprosy are dapsone, the highly bactericidal rifampicin and clofazimine. Prothionamide (or ethionamide) is also widely used especiaily in the recently advocated multidrug regimens. Other second-line drugs are thiacetazone and thiambutosine $^{1}$ but the latter is already obsolete. Mycobacterium leprae resistant to all of these drugs ${ }^{1,2}$ and multidrug combinations (reported to XIIth International Leprosy Congress) have been reported. The widespread emergence of both primary and secondary dapsone resistance is of particular concern. ${ }^{1,3}$ Another cause for anxiety is the range of side-effects associated with some of the drugs available. ${ }^{4}$ The potential for chronic damage is considerable and the need for clinical monitoring especially with rifampicin is now well known. Nevertheless effective treatment of leprosy is possible and the use of multidrug and pulsed therapy may require much shorter periods of treatment than was at first thought especially for multibacillary cases. ${ }^{5}$ Why then the need for new chemotherapeutic agents? In the first place multidrug resistant strains of $M$. leprae are now a real possibility. Secondly, none of the existing drugs clear the 'persister' organisms. Thirdly, drugs with fewer side-effects are required for extensive treatment requiring less intensive clinical oversight. Fourthly, the cost of rifampicin and clofazimine in some countries is still too high for them to be used on the scale necessary to achieve control of the disease. Fifthly, the development and testing of an eff ective vaccine and its use in the field is still a long way off despite intensive efforts in this area.

Antileprotic drug research has, until recently, been concerned in the main, with the development of new agents derived from or based on the current drugs. ${ }^{3,6}$ Seydel and co-workers have demonstrated in a series of elegant experiments that dapsone and some novel sulphonamides act at the uniquely sensitive pteroate synthetase enzyme of 'M. lufu' and M. leprae. ${ }^{7}$ Interestingly they have shown that dihydrofolate reductase inhibitors, which have no antileprotic activity of their own, exhibit a pronounced synergistic effect with dapsone. Dapsone and bromdiaprim (a dihydrofolate reductase inhibitor) in combination have been shown to be effective clinically. ${ }^{8}$ Dapsone has however been shown, in a recent quantitative structure-active study, to have the 
optimum structure for antileprotic activity. ${ }^{9}$ It also has a good pharmacokinetic profile. Any significant improvement in the sulphone series therefore appears unlikely. Ansamycin, an analogue of rifampicin, has also been shown to possess high activity. ${ }^{10}$ Its longer half-life in man would be of advantage provided this was not associated with a greater incidence of undesirable side-effects. Recently analogues of thiacetazone, lacking the sulphur atom, thought to be responsible for toxicity, have been prepared. ${ }^{11}$ They have yet to be fully evaluated but could provide useful alternative therapeutic agents.

A major problem, with all thesecompounds, is that they would not be expected to be effective against organisms which are resistant to current drugs.

The problem with attempts to develop completely new drugs is to identify new lead compounds as quickly as possible. Only recently have good in vitro test systems, which would allow screening of new compounds on a moderate scale, become available. ${ }^{12}$ The characteristics of any new agents which are desperately needed ${ }^{13}$ are that they should be: (i) bactericidal rather than merely bacteriostatic and destroy persister organisms; (ii) effective orally; (iii) parasite specific and therefore have few side-effects; (iv) cheap to produce and formulate.

Potential lead compounds may be identified in several ways. Random screening is not possible due to the limited facilities and in any case is uneconomic and no longer necessary. Usef ul clues about new compounds can come from an understanding of the biochemistry of $M$. leprae. It is only recently, with the increased availability of bacilli from armadillos, that such studies have been possible. There is still much to learn in this area. Other leads could come from natural products which have proved eff ective in leprosy. Prabhakaran ${ }^{1,13}$ has identified a unique melanin producing tyrosinase enzyme system in $M$. leprae which utilises L-dopa as its substrate, and although this work was, and remains, controversial it suggests that new drugs related to the enzyme substrate, dopa(1),

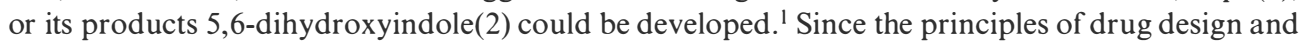
irreversible enzyme inhibition are now well established ${ }^{14}$ it should be possible to design compounds which are selective enzyme-activated irreversible inhibitors of this system. Such compounds would be expected to be bactericidal rather than simply bacteriostatic. The recent disclosure ${ }^{15}$ of antileprotic activity of the fructose derivative of serotonin(3) agrees with this line of reasoning. This compound is a natural metabolite of serotonin with few side-effects in man. It is active orally in man and the mouse, but unfortunately is only bacteriostatic. Recently in vitro tests on a series of indole compounds specifically designed as antileprotic drugs have demonstrated significant activity (M Hooper, PR Mahadevan-unpublished data). Since man also possesses tyrosinase enzymes the question of parasite/host selectivity is a real one. However biochemical studies have indicated that the putative enzyme in $M$. leprae is stereochemically and electronically less selective than the host enzyme. This is consistent with the more primitive phylogenic status of M. leprae. ${ }^{1,13}$

Recent studies of the cell wall structure of mycobacteria generally and M. leprae in particular have identified novel elements not present in other species of bacteria. ${ }^{16}$ The structure of the peptidoglycan of mycobacteria shows that meso-diaminopimelic acid(4) plays an extensive part in both the individual chains of the peptidoglycan and in their cross linking. The cross-linking of the peptidoglycan chains in other bacteria involves a D-alanyl-D-alanine terminus and a glycine residue. The transpeptidase which utilizes $\mathrm{D}$-alanyl-D-alanine as its substrate is a major site for the action of penicillins and cephalosporins which are now known to function as active-site irreversible inhibitors of this enzyme. The weak activity of $\beta$-lactam antibiotics against mycobacteria may be a reflection of the low incidence of such sites in these organisms. However there has recently ${ }^{17}$ been a report of amoxicillin in combination with clavulanic acid (a $\beta$-lactamase inhibitor) showing significant in vitro activity against $M$. tuberculosis. The resistance of mycobacteria to penicillins may therefore be due to lactamase activity.

The unusual glycolyl muramic acid derivative in mycobacteria may provide another site for drug design.

Since mammalian cells lack a cell wall comparable with that of mycobacteria it is reasonable to expect that new drugs derived from such structures will be highly parasite specific. 
M. leprae also has present in its cell wall a variety of novel lipids, fatty acids and their complex derivatives. ${ }^{18}$ Some of these are covalently bound into the wall whilst others are more labile. Any disturbance of the organism's metabolism of these compounds would be expected to cause some defect of cell wall function resulting in loss of viability of the bacillus. Indeed thiacetazone, thiambutosine and ethionamide are thought to act in this way. Recently chaulmoogric acid(5), a major constituent of oil of chaulmoogra, has been shown to be incorporated into the cell wall lipids of various mycobacteria. ${ }^{19}$ The resultant changes in the cell wall structure could be the basis of the known bacteriostatic activity of the compound. Once again, since these lipids are unique to mycobacteria, there is a possibility of selectively active analogues of chaulmoogric acid being developed.

Electron micrographs of $M$. leprae in sections of host tissue show distinctive electron transparent zones round the bacilli. This now appears to be due to large quantities of potent antigenic glycolipids with unique structural features. ${ }^{20}$ The production of large amounts of this compound by the bacillus provides another possible target for drug design. The electron transparent sheath may disguise many other antigenic features of the bacillus and thereby render it less susceptible to the host's immune system. Its removal by chemotherapeutic agents would be expected to increase the effective recognition and destruction of the bacillus.

The structure and biochemistry of $M$. leprae and the physiology of leprosy are being vigorously studied at present. From these studies other targets for drug development would be expected to emerge. The major requirement will then be for that discernment which will identify new structures which will best meet the above criteria for new antileprotic agents. The future prospects for the development of new antileprotic drugs are good given modest funding to support this kind of work.<smiles>[NH3+]C(Cc1ccc(O)c(O)c1)C(=O)[O-]</smiles><smiles>Oc1cc2cc[nH]c2cc1O</smiles><smiles>Oc1ccc2[nH]cc(CCNCC3(O)OCC(O)C(O)C3O)c2c1</smiles>

4<smiles>NC(CCCC(N)C(=O)[O-])C(=O)[O-]</smiles>

5<smiles>O=C(O)CCC1C=CCC1</smiles> 


\section{References}

${ }^{1}$ Hooper M, Purohit MG. The chemotherapy of leprosy. In Progress in Medicinal Chemistry, Ellis GP, West GB (eds), Elsevier, Amsterdam: 1983; 20: 1-81.

2 Warndorff-Van Diepen T. Clofazimine-resistant leprosy. Int J Lepr, 1982; 50: 139.

3 Special programme for research and training in tropical diseases. Sixth programme report Leprosy (1979-82) Geneva; WHO 1983; 8: 209-96.

4 Jopling WH. Side-effects of antileprosy drugs in common use. Lepr Rev, 1983; 54: 261.

5 WHO Report on chemotherapy of leprosy control programmes. Technical report series 675, Geneva, 1982. Yawalkar SJ, McDougall AC, Languillon J, et al. Once-monthly rifampicin plus daily dapsone in initial treatment of lepromatous leprosy. Lancet, 1982; 1: 1199.

${ }^{6}$ Shepard CC, Van Landingham RM, Walker LL. Recent studies of antileprosy drugs. Lepr Rev, 1983; 54; (special issue) 23S.

7a Seydel JK, Wempe EG. Bacterial growth kinetics of ' $M$. luf u' in the presence and absence of various drugs alone and in combination. A model for the development of combined chemotherapy against M. leprae. Int J Lepr, 1982; 50: 20.

7b Kulkarni VM, Seydel JK, Coats EA. Mode of action of dapsone in E. coli and in dapsone-sensitive and dapsone-resistant strains of 'M. lufu;, M. smegmatis ATCC 607 and $M$. leprae - a comparison (Abstract X/435) 12th International Leprosy Congress, New Delhi, Feb, 20-25th, 1984.

${ }^{8}$ Rosenfeld M, Wempe E, Seydel JK. Systems for the development of drug combinations and quantification of synergistic, additive and antagonistic effects. (Abstract X/416) 12th International Leprosy Congress, New Delhi, Feb 20-25th, 1984.

${ }^{9}$ Bawdon, D, Tute MS. Structure-activity relationships of antimycobacterial sulfones: a study using physiochemical constants. Eur J Med Chem, 1981; 16: 299.

10 Jacobson RR, Hastings RC. Activity of ansamycin against M. leprae in mice. Lancet, 1983; ii: 1079.

11 Schaper KJ. Investigation of thiosemicarbazones and their analogues as potential inhibitors of deoxyribonucleotide synthesis of mycobacteria (Abstract X/421) 12th International Leprosy Congress, New Delhi, Feb 20-25th, 1984.

12 Beeching NJ, Ellis CJ. Leading article, J Antimicrob Chemotherap, 1982; 10: 81.

13 Prabhakaran K, Harris EB, Kirchheimer WF. Microbios, 1972; 5: 273. Prabhakaran K. Lepr Rev. 1977; 48: 145 and references cited therein.

14 Seiler N, Jung MJ, Koch-Weser J, (eds). Enzyme-activated irreversible enzyme inhibitors, New York, Elsevier, North Holland, 1978.

15 Mester L, Balakrishnan S, Saint-Andre P, Mester M. Desoxyfructoserotonin: a new drug with anti-leprosy activity. Annales de Microbiologie, 1982; 133B: 427.

${ }^{16}$ Draper P. The anatomy of mycobacteria. In Ratledge C, Stanford J, (eds). The biology of the Mycobacteria, vol 1. London Academic Press 1982; pp. 9-52.

17 Cynamon MH, Palmer GS. In vitro activity of amoxicillin in combination with clavulanic acid against M. tuberculosis. Antimicrob Agents Chemother, 1983; 24: 429.

18 Ratledge C. Lipids; cell composition, fatty acid biosyntheses. In Ratledge C, Stanford J, (eds). The biology of the Mycobacteria, vol 1. London Academic Press 1982; pp. 53-93. Minnikin DE. Lipids: complex lipids, their chemistry, biosynthesis and roles. In Ratledge C, Standford J (eds). The biology of the Mycobacteria, vol 1. London Academic Press 1982; pp. 95-184.

19 Goucher CR, Cabot MC. Chaulmoogric acid: assimiliation into the complex lipids of mycobacteria. Lipids, 1981; 16: 146.

${ }^{20 a}$ Hunter SW, Brennan PJ. A novel phenolic glycolipid from M. leprae possibly involved in immunogenicity and pathogenicity. J Bact 1981; 147: 728.

$20 \mathrm{~b}$ Brennan PJ. The phthiocerol-containing surface lipids of $M$. leprae-a perspective of past and present work. Int J Lepr 1983; 51: 387. 